\title{
Should Foreign Capital Be Taxed for Fiscal Expansion?
}

\author{
Michael Ka-yiu Fung* \\ The Chinese University of H ong Kong \\ Jinli Zeng* \\ The National University of Singapore
}

\begin{abstract}
This paper studies the income distribution implications of a fiscal expansion financed by foreign capital in a small open economy. Utilizing a multi-sector gen eral equilibrium model, four results are derived for a stable equilibrium: (1) domestic private agents' welfare may be reduced by fiscal expansion even if agents do not finance the expansion; (2) the fiscal authority's welfare may be reduced by fiscal expansion even if more resources are allocated for the authority's consump tion; (3) the after-tax rental income of the foreign capital's owners may be increased even if they finance the fiscal expansion; and (4) fiscal spending may be contractionary for domestic residents ( private agents and fiscal authority) even if the spending is financed by non-residents. (JEL Classification: F20, H30)
\end{abstract}

\section{Introduction}

A strategy governments in developing economies ${ }^{1}$ can employ to raise 
revenue is to reduce or eliminate the tax credits enjoyed by foreign capital. The standard counter-argument is that, since capital is internationally mobile in the long run, such taxation may induce capital outflow or inhibit further capital inflow in the future. However, it is observed that the international mobility of capital is quite limited in the short run. ${ }^{2}$ Given the presence of this immobility, does it imply that foreign capital can be taxed to finance fiscal expansion at least in the short run? This paper addresses this question. ${ }^{3}$

Utilizing a multi-sector general equilibrium model, four results are derived for a stable equilibrium: (1) domestic private agents' welfare may be reduced by fiscal expansion even if agents do not finance the expansion; (2) the fiscal authority's welfare may be reduced by fiscal expansion even if more resources are allocated for the authority's consumption; (3) the aftertax rental income of the foreign capital's owners may be increased even if they finance the fiscal expansion; and (4) fiscal spending may be contractionary for domestic residents (private agents and fiscal authority) even if the spending is financed by non-residents.

The paper is organized as follows. The model is set up in the next section. The implications of a fiscal expansion financed by foreign capital are derived in section III. Concluding remarks are provided in section IV.

\section{The Basic Model}

Consider a small open economy (SOE) in which two types of commodities are produced: a composite traded good $(Y)$ and one nontraded good (X). ${ }^{4}$ The price of the composite traded good is normalized to one and the price of the nontraded good is denoted as $p$. Production functions for $X$ and 
$Y$ are assumed to be linearly homogeneous. There are two or more factors of production which can be either intersectorally mobile or sector specific. The economy's factor endowment is fixed. One of the intersectorally mobile factors, capital, is assumed to be either domestically or foreign owned. When capital is imported, the economy's supply of capital $K$ consists of the endowment $K_{-}$and the inflow of foreign capital $K^{*}$, i.e. $K=K_{-}+K^{*}$. $M$ arkets are perfectly competitive. The total value of output in terms of the composite traded good is represented by a standard revenue function, $R(p, K)$. There are no distortions, and the properties of the revenue function follow as: $R_{p}=X$ (the nontraded good's production), $R_{p p}=\partial X / \partial p>0, R_{K}=r$ (the rental rate of capital) $>0$, and $R_{K p}=\partial X / \partial K=\partial r / \partial p$. There may be more than two factors in the economy, in which case the nontraded good is (is not) relatively capital intensive if $R_{k p}>(<) 0$. It is further assumed that the rental income of foreign capital is fully repatriated. ${ }^{5}$

There is a representative private agent in the economy, who is endowed with fixed amounts of production factors. The agent's utility is defined on the consumption of two final goods, $C^{X}$ and $C^{Y}$, which are assumed to be normal goods. $E(p, u)$ is the minimum expenditure necessary for the agent to achieve a given utility level, $u$, when the nontraded good's price is $p$. Assuming all usual properties of the utility function are satisfied, the following properties of the expenditure function can be derived: $E_{p}=C^{x}$ (the private demand for the nontraded good), $E_{p p}=\partial C^{x} / \partial p<0, E_{u}>0, E_{p u}>0$, and $\mathrm{E}_{\mathrm{uu}}<0$.

We follow Chao and Yu [1993] in modeling the government authority's optimizing behavior for given government revenue, G. We also define the fiscal authority's utility ${ }^{6}$ on the consumption of two final goods, $G^{X}$ and $G^{Y}$, which are also assumed to be normal. $B(p, v)$ is the minimum expenditure necessary for the fiscal authority to achieve a given utility level, $v$, when the 
0 , and $\mathrm{B}_{\mathrm{v}}<0$.

Following Helpman [1976, 1977] and Chao and Yu [1993], government spending (G_) finances pure government consumption, ${ }^{7}$ which does not include the provision of public goods or public inputs. Additionally, we assume that fiscal spending is tax-financed such that the government budget is balanced, i.e. fiscal spending equals taxation revenue. We assume no indirect taxation, so that all taxation revenue derives from direct taxes imposed on the private agent ${ }^{8}$ and the owners of foreign capital. We use $T^{\mathrm{F}}$ and $T^{D}$ to denote tax revenue collected from, respectively, the owners of foreign capital and the private agent, such that the government budget is balanced:

$$
G_{-}=T^{F}+T^{D}
$$

and

$$
T^{\mathrm{F}}=\mathrm{tR}_{\mathrm{K}}(\mathrm{p}, \mathrm{K}) \mathrm{K}^{*}
$$

where $0<t<1$ is the rate of capital income tax imposed on the owners of foreign capital and hence $R_{K}$ is the pre-tax return to foreign capital.

$\mathrm{G}$ is taken to be exogenous; however, we shall consider the effects of a tax-financed fiscal expansion, i.e. an increase in $\mathrm{G}$.

Since foreign capital is assumed to be immobile, the general equilibrium of the economy can be represented by (1), (2), and the following equations:

$$
\begin{aligned}
& B(p, v)=p G^{X}+G^{Y}=G_{-} \\
& E(p, u)=R(p, K)-R_{K}(p, K) K^{*}-T^{D} \\
& E_{p}(p, u)+G^{X}=R_{p}(p, K)
\end{aligned}
$$

(3) implies that government expenditure equals government revenue, (4) that the private aqent's expenditure equals national income minus the tax pav- 
vate agent's demand, $C^{x}$, plus the government's demand, $G^{x}$, equal to the supply X. The economy's budget constraint is obtained by adding (3) and (4):

$$
E(p, u)+B(p, v)=R(p, K)-(1-t) R_{K}(p, K) K^{*} .
$$

We have five equations, (1)-(5), five endogenous variables, $p, v, u, t$ and $\mathrm{T}^{\mathrm{D}}$ (or $\mathrm{T}^{\mathrm{F}}$ ), and two policy variables, G_and $\mathrm{T}^{\mathrm{F}}\left(\operatorname{or} \mathrm{T}^{\mathrm{D}}\right) .{ }^{9}$

\section{Welfare Effects of a Fiscal Expansion Financed by Foreign Capital}

In this section, we discuss the income implications of a tax-financed fiscal expansion when additional expenditure is solely financed by foreign capital,

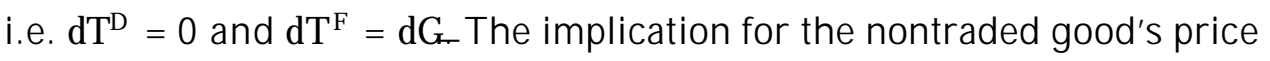
will first be considered, because of its importance in the welfare analysis. ${ }^{10}$ From (1)-(5), we can show that fiscal expansion must increase the nontraded good's price:

$$
d p / d G_{-}=-E_{u} B_{v} \gamma /(\Delta p)>0
$$

where $\Delta=E_{u} B_{v}\left(E_{p p}+B_{p p}-R_{p p}\right)+B_{v} E_{p u}\left(B_{p}-K^{*} R_{p k}\right)-E_{u} B_{p v} B_{p}=E_{u} B_{v} X\left[\left(1-\alpha_{X G}\right) e_{p}+\right.$ $\left.\alpha_{X G} \zeta_{p}-\varepsilon_{p}+(m-\gamma) \alpha_{X G}-m \eta_{k *} \varepsilon_{k}\right] / p, 0<m=p E_{p u} / E_{u}<1$ is the private agent's marginal propensity to consume the nontraded good, $0<\gamma=p_{p v} / B_{v}<1$ is the fiscal authority's marginal propensity to consume the nontraded good, 0 $<\alpha_{X G}=G^{X} / X<1$ is the share of the government demand for the nontraded good in the SOE's supply of the good, $e_{p}=p E_{p p} / C^{x}<0$ is the compensated elasticity of the private demand for the nontraded good with respect to its own price, $\zeta_{p}=\mathrm{pB}_{\mathrm{pp}} / \mathrm{G}^{\mathrm{X}}<0$ is the compensated elasticity of the government demand for the nontraded good with respect to its own price, $0<\varepsilon_{\mathrm{p}}=\mathrm{pR}_{\mathrm{pp}} / \mathrm{X}$ is the elasticity of the nontraded good's supply with respect to its own price, $\varepsilon_{K}=K R_{n k} / X$ is the elasticity of the nontraded good's supply with respect to 
of the nontraded good is (is not) relatively capital intensive, and $0<\eta_{K^{*}}=$ $\mathrm{K}^{*} / \mathrm{K}<1$ is the share of the foreign capital in the economy's supply of capital. It is shown in the appendix that the stability of the nontraded good's market requires $\Delta<0$.

In the standard transfer problem 〈see Chao and Yu [1993]), the price effect of fiscal spending depends on both the fiscal authority's and the consumer's marginal propensities to consume the nontraded good. However, (6) indicates that the price effect depends only on the fiscal authority's marginal propensity to consume the nontraded good when the fiscal expenditure is solely financed by foreign capital. The intuition behind (6) can be easily understood, since the rise in fiscal income increases the authority's demand for the nontraded good but has zero direct effect on the private agent's demand for the nontraded good under the assumed means of financing the fiscal expenditure. We shall show that the magnitude of the price increase plays an important role in the determination of welfare effects.

Consider now the implications for incomes of the private agent, the fiscal authority, and the owners of foreign capital. First, from (4) and (6), the policy effect on the private agent's real income ${ }^{11}$ is expressed as follows:

$$
E_{u}(d u / d \bar{G})=\left(B_{p}-K^{*} R_{p k}\right) d p / d \bar{G}=-\frac{E_{u} B_{v} X}{p \Delta}(x G-k * k)
$$

In equation (7), $B_{p} d p / d G_{-}\left(\right.$or $-\alpha_{x G} \gamma E_{u} B_{v} X /(p \Delta)$ ) is the positive revenue effect on the private agent's real income, by which a rise in the nontraded good's price increases the private agent's real income from selling the nontraded good to the government. $-K^{*} R_{p k} d p / d G_{-}\left(\right.$or $\eta_{K^{*}} \varepsilon_{k} \gamma E_{u} B_{v} X /(p \Delta)$ ) denotes the rental payment effect by which the price increase also changes the rental payment to foreign capital. The relationship between the nontraded good's price and the rental payment depends on the nontraded good's factor intensitw If tho nontradod nond ic lic notl rolativaly ranital intanciuso tho nolire- 
Proposition 1: Provided that the stability condition is satisfied and the non traded good is relatively capital intensive, the domestic private agent's real income may be decreased by a fiscal expansion with foreign capital even if the agent does not finance the expansion.

An implication is that the private agent may lobby against the fiscal expansion, even if the expansion is financed by non-residents.

From equations (6) and (7) and the expression for $\Delta$, we can see that the policy-induced change in the private agent's real income has repercussions in terms of the increase in the nontraded good's price. ${ }^{12}$ When the private agent's real income is increased (decreased), there is a corresponding magnification (reduction) of the price increase. Accordingly, we may expect the good's price to increase by a larger (smaller) magnitude. From our specification, a larger magnitude of the private agent's marginal propensity to consume the nontraded good, i.e. $\mathrm{m}$, implies a larger change in the private agent's demand for nontraded good and then a larger magnifying (mitigating) effect on the price increase. According to our discussion, we have the following lemma and we shall show that this lemma is very useful to understand the implications of fiscal expansion:

Lemma 1: When $\alpha_{x G}-\eta_{K *} \varepsilon_{K}>(<)$, there is a magnifying ( mitigating) effect on the price increase. The larger the private agent's marginal propensity to con sume the nontraded good, i.e. $m$, the larger will be the magnitude of the effect.

Second, from (3) and (6), the effect on the fiscal authority's real income is as follows:

$$
\begin{aligned}
B_{v}(d v / d \bar{G}) & =\left[1-B_{p}(d p / d \bar{G})\right] \\
& =B_{v}\left[\left(B_{p}-K^{*} R_{p k}\right) E_{p u}+E_{u}\left(E_{p p}+B_{p p}-R_{p p}\right)\right] / \Delta
\end{aligned}
$$




$$
=\frac{E_{u} B_{v} X}{p \Delta}\left[m\left(x G-k^{*} k\right)+\left(1-x_{G}\right) e_{p}+x_{G} p^{-}{ }_{p}\right]
$$

The first term, 1, on the right hand side of the first equality in (8) represents a positive fiscal income effect, since an increase in G_implies more resources are allocated for the fiscal authority's consumption. The second term, $-B_{p}(d p / d G)$, represents the negative price-induced effect due to the reduction in the fiscal authority's real income which in turn is due to the rise in the nontraded good's price. The net effect on the authority's welfare depends on the interaction between these two effects.

Conditions with different income implications for the fiscal authority in a stable equilibrium are presented in Table 1 . We may expect that the fiscal authority's real income will be increased by fiscal expansion since more resources are allocated for the authority's consumption. According to (8), this will be the case if the direct fiscal income effect dominates the priceinduced effect. Two different sets of conditions can lead to the result. First, $\alpha_{X G}-\eta_{K^{*}} \varepsilon_{K}<0$ which implies, from Lemma 1, a mitigating effect on the price increase and hence the price-induced effect is dominated. Second, $\left(\alpha_{X G}-\eta_{K^{*}} \varepsilon_{K}\right)<0$ with $\tilde{\sigma}>m$ (where $\tilde{\sigma} \equiv\left[\varepsilon_{p}-\left(1-\alpha_{X G}\right) e_{p}-\alpha_{X G} \zeta_{p}\right] /\left(\alpha_{X G}-\right.$ $\left.\left.\eta_{k * \varepsilon_{K}}\right)\right) \cdot{ }^{13}$ According to Lemma 1 , the condition leads to a magnifying effect on the price increase, however, the magnitude of this effect is sufficiently small such that the price-induced effect is also dominated.

\section{Table 1}

\section{Welfare Implication on the Fiscal Authority of a Fiscal}

Expansion Financed by Foreign Capital

\begin{tabular}{|l|l|l|}
\hline \multirow{2}{*}{$\varepsilon_{K}<0$} & \multicolumn{2}{|c|}{$\varepsilon_{K}>0$} \\
\cline { 2 - 3 } & $\alpha_{X G}-\eta_{K *} \varepsilon_{K}<0$ & $\alpha_{X G}-\eta_{K} * \varepsilon_{K}>0$
\end{tabular}


A different result, i.e. $B_{v}(d v / d G)<0$, can be obtained in a stable equilibrium when the rise in the nontraded good's price is sufficiently high such that the indirect price-induced effect can dominate the direct fiscal income effect. The necessary condition for this "perverse" result to happen is an increase in the private agent's real income, i.e. $\left(\alpha_{X G}-\eta_{K^{*}} \varepsilon_{K}\right)>0$, such that there is reinforcement of the price increase. When the magnitude of this reinforcement effect is sufficiently large, i.e. $m>\tilde{\sigma}$, the direct fiscal income effect can be dominated and then the fiscal authority's real income can be reduced by the fiscal expansion. According to our discussion, we have the following proposition:

Proposition 2: Provided that the stability condition is satisfied, the fiscal authority's real income may be decreased by a fiscal expansion in a SOE with foreign capital even if more resources are allocated for the authority's con sumption.

The interesting feature of this above result is that the authority's real income can decline only if the fiscal expansion improves the private agent's welfare. Hence, our results indicate a conflict of interest between the domestic private agent and the fiscal authority in the process of fiscal expansion even if the expansion is financed by non-residents.

Third, the income consequences for owners of foreign capital can be expressed as follows:

$$
\begin{aligned}
& d\left[(1-t) K^{*} R_{K}\right] / d \bar{G}=K{ }^{*} R_{K p}(d p / d \bar{G})-1 \\
& \quad=-E_{u} B_{v} X\left[(m-)\left(x G-K^{*} K\right)+(1-x G) e_{p}+x G p_{p}\right] /(\Delta p)
\end{aligned}
$$

The first term, $K^{*} R_{k p}(d p / d G)$, on the right side of the first equality of (9) represents the price-induced rental payment effect which increases (de- 
Table 2

Income Implication on the Owners of Foreign Capital of a Fiscal Expansion Financed by Them

\begin{tabular}{|c|c|c|c|c|c|}
\hline \multirow{2}{*}{} & \multirow{2}{*}{$\varepsilon_{\mathrm{K}}<0$} & \multicolumn{4}{|c|}{$\varepsilon_{\mathrm{K}}>0$} \\
\cline { 3 - 6 } & & \multicolumn{2}{|c|}{$\alpha_{\mathrm{XG}}-\eta_{\mathrm{K} *} \varepsilon_{\mathrm{K}}>0$} & \multicolumn{2}{|c|}{$\alpha_{\mathrm{XG}}-\eta_{\mathrm{K} *} \varepsilon_{\mathrm{K}}<0$} \\
\cline { 3 - 6 } & & $\mathrm{m}<\tilde{\sigma}+\gamma$ & $\mathrm{m}>\tilde{\sigma}+\gamma$ & $\mathrm{m}<\tilde{\sigma}+\gamma$ & $\mathrm{m}>\sigma \tilde{\sigma}+\gamma$ \\
\hline $\mathrm{d}\left[(1-\mathrm{t}) \mathrm{K}^{*} \mathrm{R}_{\mathrm{pK}}\right]$ & - & - & + & + & - \\
\hline
\end{tabular}

If the production of the nontraded good is relatively capital intensive, the two effects are countervailing and then the implications for the income of owners of foreign capital are ambiguous. The income of owners of foreign capital will be decreased when either one of the following two sets of conditions is satisfied in case of a positive $\varepsilon_{K}$. First, $\left(\alpha_{X G}-\eta_{K^{*}} \varepsilon_{K}\right)<0$ with $m>\tilde{\sigma}+\gamma$. According to Lemma 1 , there is a sufficiently large mitigating effect on the price increase such that the price-induced effect is dominated. Second, $\left(\alpha_{X G}-\eta_{K^{*}} \varepsilon_{K}\right)>0$ with $m<\tilde{\sigma}+\gamma$. In this case, there is only a very small magnifying effect on the price increase such that the price-induced effect is dominated.

A different income implication, i.e. $d\left[(1-t) K^{*} R_{K}\right] / d G>0$, can be obtained when the rise in the nontraded good's price is sufficiently large such that the indirect price-induced effect can dominate the direct taxation effect. The price-induced effect will be large enough to dominate the other effect when there is a magnifying (mitigating) effect on the price increase with a sufficiently large (small) magnitude. According to (9) and Lemma 1 , it is the case when $\varepsilon_{K}>0$ and $\left(\alpha_{X G}-\eta_{K *} \varepsilon_{K}\right)<(>) 0$ with $m<(>) \widetilde{\sigma}+\gamma$. This implies 
residents must be expansionary. Following Chao and Yu [1993],14 a fiscal expansion is said to be expansionary (contractionary) if the fiscal expansion increases (decreases) the total real income of the private agent and the fiscal authority, i.e. $E_{u}(d u / d G)+B_{v}(d v / d G)>(<) 0$. Since there is no distortion in the economy, the tax-financed fiscal expansion is a zero-sum income redistribution process between domestic residents and non-residents in the SOE. According to (7), (8) and (9), it is shown that $E_{u}(d u / d G)+B_{v}(d v / d G)=$ $-d\left[(1-t) R_{k} K^{*}\right] / d G_{-}$and then the policy-induced gain (loss) in terms of real income of the SOE's residents (including the private agent and the fiscal authority) equals the policy-induced loss (gain) in the after-tax rental income of the owners of foreign capital in the SOE. Since the income of owners of foreign capital in the SOE can be increased by the policy, the following proposition is immediate:

Proposition 4: Provided that the stability condition is satisfied and the non traded good is relatively capital intensive, fiscal spending which is financed by non-residents can be contractionary in a SOE.

The conventional wisdom seems to suggest that the fiscal expansion will be expansionary when spending is financed by non-residents; however, we have shown that this is not necessarily the case even in a distortion-free and stable environment. Conditions under which fiscal expansion are expansionary or contractionary are shown in Table 3.

Table 3

Income Implication on the SOE of a Fiscal Expansion Financed by Foreign Capital

\begin{tabular}{|l|l|l|}
\hline \multirow{2}{*}{$\varepsilon_{\nu}<0$} & \multicolumn{2}{|c|}{$\varepsilon_{K}>0$} \\
\cline { 2 - 3 } & $\alpha_{v r}-n_{\nu *} \varepsilon_{\nu}>0$ & $\alpha_{v r}-n_{\nu *} \varepsilon_{\nu}<0$
\end{tabular}




\section{Concluding Remarks}

We have utilized a two-sector general equilibrium model to study the income distribution implications of a fiscal expansion financed by foreign capital in a small open economy. O ur study shows that, in a distortion-free and stable environment, a fiscal expansion financed by foreign capital may harm domestic residents ${ }^{15}$ even when foreign capital is immobile.

\section{Appendix}

Following Dei [1985], the adjustment process for demand for nontraded good is

$$
\dot{p}=a Z(p)
$$

where the dot represents the time derivative, $a$ is a positive constant and $Z=$ $B_{p}(p, v)+E_{p}(p, u)-R_{p}(p, K)$ denotes the excess demand for nontraded good. We can represent $u$ and $v$ in terms of $p$. By keeping $G_{-}$and $t$ constant, we can take a linear approximation of the above adjustment process around the equilibrium point $p^{*}$ as

$$
\dot{p}=a(d Z / d p)\left(p-p^{*}\right)
$$

Hence, the necessary and sufficient condition for stability of the system is

$$
\mathrm{dZ} / \mathrm{dp}<0
$$

From (3), (4), and (5), we obtain

$$
d Z / d p=\Delta / E_{u} B_{v}
$$

where $\Delta=E_{u} B_{v}\left(E_{p p}+B_{p p}-R_{p p}\right)+B_{v} E_{p u}\left(B_{p}-K^{*} R_{p k}\right)-E_{u} B_{p v} B_{p}=E_{u} B_{v} X\left[\left(1-\alpha_{X G}\right)\right.$ 
$m\left(\alpha_{X G}-\eta_{K *} \varepsilon_{K}\right)$ represents how the change in the private agent's real income due to the increase in $p$ affects the agent's demand. When $m\left(\alpha_{x G}-\right.$ $\eta_{K} * \varepsilon_{K}$ ) has a positive and sufficiently large magnitude, the private agent's demand for the nontraded good will be increased and it may lead to an unstable system. Second, the term $-\left(\gamma \alpha_{x G}\right)$ represents how the reduction in the fiscal authority's real income due to the rise in $p$ affects the authority's demand. When this term has a large absolute magnitude, the reduction in the fiscal authority's demand for the nontraded good can guarantee the stability of the system.

\section{References}

Beladi, H. and C.C. Chao [1993], "Non-traded goods, Urban Unemployment and Welfare in LDCs," European Journal of Political Economy 9; pp. 281-292.

Bovenberg, A. L. and R. H. Gordon [1993], "Why is Capital so Immobile Internationally?: Possible Explanations and Implications for Capital Income Taxation," Working paper.

Chao, C.C. and E.S.H. Yu [1993], "Can Fiscal Spending be Contractionary in the Neo-classical Economy?" E conomica 60; pp. 347-356.

Dei, F. [1985], "Voluntary Export Restraints and Foreign Investment," Jour nal of International Economics 19; pp. 305-312.

Devereux, M. [1988], "Non-traded Goods and the International Transmission of Fiscal Policy," Canadian Journal of Economics 21; pp. 265-278.

Helpman, E. [1976], "M acroeconomic Policy in a Model of International Trade with a Wage Restriction," International Economic Review 17; pp. 262-277.

Helpman, E. [1977], “Nontraded Goods and M acroeconomic Policy under a 
Research Observer 7; pp. 59-78.

Sellin, P., and I. M. Werner [1993], "International Investment Barriers in General Equilibrium," Journal of International E conomics 34; pp. 137151. 